\title{
Parents as Agents of Change (PAC) in pediatric weight management: The protocol for the PAC randomized clinical trial
}

Geoff D C Ball ${ }^{*}$, Kathryn A Ambler ${ }^{2}$, Rachel A Keaschuk ${ }^{3}$, Rhonda J Rosychuk ${ }^{4}$, Nicholas L Holt ${ }^{5}$, John C Spence ${ }^{6}$, Mary M Jetha ${ }^{7}$, Arya M Sharma ${ }^{8}$ and Amanda S Newton ${ }^{9}$

\begin{abstract}
Background: There is an urgent need to develop and evaluate weight management interventions to address childhood obesity. Recent research suggests that interventions designed for parents exclusively, which have been named parents as agents of change (PAC) approaches, have yielded positive outcomes for managing pediatric obesity. To date, no research has combined a PAC intervention approach with cognitive behavioural therapy (CBT) to examine whether these combined elements enhance intervention effectiveness. This paper describes the protocol our team is using to examine two PAC-based interventions for pediatric weight management. We hypothesize that children with obesity whose parents complete a CBT-based PAC intervention will achieve greater reductions in adiposity and improvements in cardiometabolic risk factors, lifestyle behaviours, and psychosocial outcomes than children whose parents complete a psycho-education-based PAC intervention (PEP).
\end{abstract}

Methods/Design: This study is a pragmatic, two-armed, parallel, single-blinded, superiority, randomized clinical trial. The primary objective is to examine the differential effects of a CBT-based PAC vs PEP-based PAC intervention on children's BMI z-score (primary outcome). Secondary objectives are to assess intervention-mediated changes in cardiometabolic, lifestyle, and psychosocial variables in children and parents. Both interventions are similar in frequency of contact, session duration, group facilitation, lifestyle behaviour goals, and educational content. However, the interventions differ insofar as the CBT-based intervention incorporates theory-based concepts to help parents link their thoughts, feelings, and behaviours; these cognitive activities are enabled by group leaders who possess formal training in CBT. Mothers and fathers of children (8-12 years of age; BMI $\geq 85^{\text {th }}$ percentile) are eligible to participate if they are proficient in English (written and spoken) and agree for at least one parent to attend group-based sessions on a weekly basis. Anthropometry, cardiometabolic risk factors, lifestyle behaviours, and psychosocial health of children and parents are assessed at pre-intervention, post-intervention, 6-, and 12-months follow-up.

Discussion: This study is designed to extend findings from earlier efficacy studies and provide data on the effect of a CBT-based PAC intervention for managing pediatric obesity in a real-world, outpatient clinical setting.

Trial Registration: ClinicalTrials.gov identifier: NCT01267097

Keywords: Obesity, Pediatric, Treatment, Parents, Cognitive behavioral therapy, Canada

\footnotetext{
* Correspondence: gdball@ualberta.ca

${ }^{1} 8 \mathrm{~B}$, Pediatric Centre for Weight and Health, Edmonton General Continuing

Care Centre, 11111 Jasper Ave, Edmonton, AB, CANADA T5KOL4

Full list of author information is available at the end of the article
} 


\section{Background}

Pediatric obesity has increased dramatically in economically developed countries over the past several decades [1]. The most recent national estimates from the Canadian Community Health Survey revealed that $26 \%$ of Canadian children and youth were overweight while $8 \%$ were obese [2]. These data showed overweight and obesity increased $50 \%$ and $167 \%$, respectively, since measured height and weight data were last collected from Canadian children in the late 1970s. This is an alarming trend since a high level of body fat in children and youth is linked to numerous adverse health outcomes including high blood pressure, dyslipidemia, insulin resistance, and non-alcoholic fatty liver disease [3]. In addition to the high proportion of boys and girls impacted by obesity-related medical comorbidities, the psychosocial consequences of having an unhealthy weight are likely most salient for families. A number of reports have studied the connections between pediatric obesity and depression [4,5], anxiety [5], selfesteem [6], body image [7], executive functioning [8], as well as bias and stigmatization $[9,10]$. Collectively, this body of evidence highlights the variety of factors that influence the health and well-being of children with obesity.

There have been numerous calls for the development and evaluation of pediatric weight management interventions [11-13]. Such interventions are usually designed to improve lifestyle behaviours to reduce adiposity and risk factors for chronic diseases including type 2 diabetes and cardiovascular disease. Though researchers outside of Canada have established fundamental features of pediatric weight management, their application in a Canadian context has been limited. The Canadian Obesity Clinical Practice Guidelines (CPG) reinforced this knowledge gap [11]; notably, of all the weight management research used to inform the CPG, none of the evidence was Canadian. This situation is undesirable since Canada's cultural, social, geographic, and health services uniqueness suggests that weight management interventions that work in other countries may not translate universally or successfully $[14,15]$. Despite these issues, a common theme underscored in almost every published report on pediatric weight management is the central role played by parents $[16,17]$.

Parents play an invaluable role in creating a supportive home environment to enable their children to make healthy lifestyle choices $[18,19]$. Parents also serve as important role models given that parental attitudes and behaviours regarding physical activity and nutrition can have a substantial impact, both positively and negatively, on the attitudes and behaviours of their children [20-24]. Parenting style is also an important factor that impacts child health outcomes. In research extending Baumrind's classical descriptions of parenting styles [25], children of parents who demonstrate controlling, restrictive behaviours exhibit less healthy dietary behaviours and are at increased risk of obesity versus children of parents who demonstrate more supportive, authoritative practices [26-30]. In addition, data on psychosocial stress within families suggests that improving the family system and parent-child relationships may reduce the risk of pediatric obesity [31]. Taken together, these observations support the need for weight management interventions that attend to both cognitive and behavioural factors within the family context.

The key role played by parents in pediatric weight management interventions was established in the early 1980 s by the formative research conducted by Leonard Epstein and colleagues [28,32-35]. Their work has been extended in recent years through research focused on parents as agents of change (PAC) in lieu of treating parents and children as a dyad. Intervening with parents exclusively to address other health concerns in children and youth has been applied successfully in the past [36-38], but represents a newer model for care for pediatric weight management. If parent-only interventions are as effective as interventions that include children only or parent-child dyads, a parent-only model would be the most efficient (and likely cost-effective) treatment option. Indeed, emerging evidence supports a PAC treatment approach. For instance, in a randomized, one-year study of obese $6-11$ year olds, Golan et al. [39] compared two weight management interventions (one for children exclusively versus one for parents exclusively). While children in both groups lost weight, the reduction in percent overweight was greater for children in the parent-only group compared to those in the group that included children exclusively; program adherence and retention were also superior in the parent-only group. More recently, Golan and colleagues compared child weight loss in parent-only versus parent + child groups. Obese children of parents in the parent-only group showed greater reductions in adiposity compared to children in the parent + child group, improvements that were maintained at 18-months follow-up [40]. Since these initial reports, data from larger, higher-quality clinical trials have confirmed the beneficial effects of PAC interventions in pediatric weight management [41-44].

Though the aforementioned data have highlighted the fundamental leadership role parents can play in helping their children to achieve success in pediatric weight management, the interventions have provided limited insight into how and why the interventions promote behavioural and cognitive changes [45]. The current study builds on the seminal work of Golan and colleagues by applying a PAC approach, which includes a theoreticallybased, clinical treatment modality (cognitive behavioural therapy, CBT) in comparison to the traditional psychoeducational approach that helps to interpret study 
outcomes. Although CBT has been used previously for treating pediatric obesity $[46,47]$, our study addresses family-oriented issues with parents exclusively rather than focusing on boys and girls themselves. We believe that working with parents on their own may also allay concerns regarding intervening with children (i.e., stigmatization, low motivation, a lack of identifying obesity as a health concern). Further, by evaluating a PAC CBT-based intervention in an out-patient clinical setting in our local children's hospital, the current trial is designed to expand on the promising findings from efficacy-based studies to determine the effectiveness of PAC interventions in a real-world environment, which often includes children with severe obesity. This paper describes the protocol our team is using to examine two PAC-based interventions for pediatric weight management. We hypothesize that children whose parents complete the CBT-based PAC intervention will achieve greater reductions in adiposity, improved lifestyle behaviours and psychosocial outcomes, and decreased cardiometabolic risk factors compared to children whose parents complete a psycho-education-based (PEP) PAC intervention, which is similar in content and structure to the CBT-based version, but does not include elements of cognitive behavioural therapy.

\section{Methods/Design}

This study is a pragmatic, two-arm, parallel, singleblinded, superiority randomized clinical trial. The primary objective is to examine the differential effects of CBT-based PAC vs PEP-based PAC on children's BMI z-score (primary outcome). Secondary objectives are to examine intervention-mediated changes in metabolic, behavioural, and psychosocial variables in children and parents. The RCT is conducted at the Pediatric Centre for Weight and Health (PCWH), which is an outpatient pediatric weight management clinic at the Stollery Children's Hospital (Alberta Health Services) in Edmonton, Alberta, Canada. As a clinical program that offers weight management care to boys and girls with obesity (and their families), we have used different study designs to evaluate weight management interventions in the past, which has included applying a wait-list control group [48]. However, based on our team's collective clinical and research experience, a study design that includes offering health services to families as close as possible to their entry into our clinic satisfies our institutional commitment to provide timely access to weight management health services. With this in mind, developing and comparing two PAC interventions (CBT and PEP) that are similar but distinct meets our academic aim to compare the effectiveness of two evidence-informed approaches [49].

\section{Ethical considerations}

The PAC RCT is registered with ClinicalTrials.gov (NCT01267097) and has received approval from both the Human Research Ethics Board (University of Alberta) and the Northern Alberta Clinical Trials and Research Centre. Family recruitment is conducted by a research coordinator within our weight management clinic. Informed and written consent and assent are obtained from parents and children, respectively, at the point of recruitment. Families who are referred to our weight management clinic and satisfy our inclusion criteria, but decline participation, still receive weight management health services, so no families are refused care. In recognition of families' time and effort, tokens of appreciation (i.e., gift cards to a local shopping centre) are offered to families at each data collection time point (pre-intervention, post-intervention, 6- and 12-months follow-up).

\section{Recruitment}

Families are eligible for this study if $(i)$ children are between $8-12$ years old, (ii) children present with an age- and sex-specific BMI $\geq 85^{\text {th }}$ percentile [50], (iii) at least one parent agrees to attend weekly PAC sessions for 16 weeks, and (iv) children and parents are fluent in English (verbal and written). Recruitment is conducted primarily through the $\mathrm{PCWH}$, although we also attempt to recruit families from the greater Edmonton area through advertisements (e.g., posters on local health, community, and recreation centers, mail outs to local family and pediatric medical clinics).

\section{Timeframe}

Data are collected from families at pre-intervention, post-intervention, 6-, and 12-months follow-up. For practical reasons, at each time point, data collection occurs within a 2-month window (e.g., within 8 weeks before the first PAC session, within 8 weeks after the last PAC session, and between 4 weeks before to 4 weeks after each of the 6-and 12-month follow-up time points). Clinical and research experience by our team [48] revealed that this timeframe is needed to accommodate families' schedules and clinical capacity to complete data collection, which also differentiates our real-world, comparative effectiveness research [51] from more stringent criteria that are applied in the context of efficacy studies. Data collection is completed by clinicians working within the $\mathrm{PCWH}$, and given the real-world, applied health services environment within which the study is conducted, we are unable to blind them from knowing which families are receiving the CBT- and PEP-based versions of the PAC intervention [52]. 


\section{The PAC interventions: design and delivery}

The PAC curriculum (please see Table 1) was developed using strategies consistent with intervention mapping [53] by incorporating evidence-based, lifestyle and behavioural strategies for pediatric weight management [54]. Both the CBT and PEP interventions consist of 16 weekly sessions that are offered to parents (in the evening) twice yearly (September - December; January - April). Sessions are held within our health care institution in classrooms within different areas of the hospital as a means to minimize cross-group contamination. Two healthcare professionals (e.g., dietitian, nurse, fitness professional, mental health professional) per intervention arm provide the curriculum to small groups of parents that will range in size to no more than 15 parents/group. Although at least one parent per family is required to attend the group sessions, additional parents or caregivers are welcome.

The PAC intervention includes a variety of different educational approaches such as didactic teaching, individual/private parent activities, group-based brain-storming/ problem-solving, and inter-active experiential learning. The intervention content is presented to parents through a PowerPoint ${ }^{\circledR}$ slide set; as group leaders deliver the manualized content, parents follow along with their individual parent manuals (please see Additional file 1:
Appendix for sample content from both leader and parent manuals). Leader manuals include the individual slides, information to be presented to the group, description of the aforementioned learning activities for parents, and a list of references (i.e., journal articles, books) that were used to develop the curriculum. Parent manuals include a copy of the slides, descriptions of the intervention activities, and lined spaces for parents to record notes and complete goal-setting activities on a week-byweek basis. Additional information (i.e., educational handouts, local resources) is made available for parents within the classroom on a community resource table. In lieu of potentially overloading parents with information related to nutrition, physical activity, behaviour change, and local resources for families, a decision was made by our team during the intervention development phase to limit the curriculum to what we viewed as 'need to know' information that was directly related to pediatric weight management. Information on topics that are team considered was 'nice to know' was removed from the curriculum and provided to families on the community resource table, which is intended to provide parents with optional information that parents may find interesting and relevant, but is not central to pediatric weight management and integral to helping families make healthy behaviour changes.

Table 1 An overview of the Parents as Agents of Change (PAC) intervention curriculum

\begin{tabular}{|c|c|c|}
\hline Session & Title & Content overview \\
\hline 1 & Welcome & $\begin{array}{l}\text { Introduction and orientation; parents receive pre-intervention snapshot of } \\
\text { their children's lifestyle, behavioural and metabolic health measurements, } \\
\text { which is used throughout the intervention to inform decisions regarding } \\
\text { behaviour change priorities and goal-setting }\end{array}$ \\
\hline 2 & Food For Thought & Canada's Food Guide, PAC nutrition goal \#1 (intake of vegetables and fruit) \\
\hline 3 & More Food For Thought & $\begin{array}{l}\text { Canada's Food Guide, PAC nutrition goals \#2 (intake of whole grain products) } \\
\text { and \#3 (intake of sugar-sweetened beverages) }\end{array}$ \\
\hline 4 & It's Your Move & $\begin{array}{l}\text { Canada's Physical Activity Guide for Children, PAC physical activity } \\
\text { goal \#1 (steps / day) }\end{array}$ \\
\hline 5 & Screensavers & $\begin{array}{l}\text { Canada's Physical Activity Guide for Children, PAC physical activity } \\
\text { goal \#2 (leisure time screen time) }\end{array}$ \\
\hline 6 & Portion Distortion & Food labels, serving sizes vs portion sizes \\
\hline 7 & Move It! & $\begin{array}{l}\text { Canada's Physical Activity Guide for Children, PAC physical activity } \\
\text { goal \#3 (moderate-to-vigorous physical activity) }\end{array}$ \\
\hline 8 & Staying On Track & Behaviour change relapse prevention \\
\hline 9 & Get A Cue! & Social cues influencing nutrition and physical activity \\
\hline 10 & Positive Parenting Partnerships & Limit-setting, boundaries, communication \\
\hline 11 & Community Connections & Environmental factors influencing nutrition, physical activity \\
\hline 12 & Eating Out, Eating Healthy & Menu reading, providing healthy lunches \\
\hline 13 & Feelin' Groovy! & Healthy self-esteem and body image \\
\hline 14 & Time Management & Family-based priority setting \\
\hline 15 & He Said, She Said & Bullying, sibling rivalry, peer relationships \\
\hline 16 & Ready, Set, Go! & Intervention review, future planning and goal-setting \\
\hline
\end{tabular}




\section{The PAC intervention: similarities and differences between CBT and PEP versions}

Both intervention arms in the trial are the same in frequency of contact (16 sessions), content (identical information is delivered), mode (group format), duration (60 - 90 minutes per session), intervention goals (related to nutrition and physical activity), and the number of group leaders (two per group). Importantly, the intervention arms differ in how information is conveyed to parents, and how parents work towards attempting, achieving, and maintaining healthy cognitive and behavioural changes. All families are encouraged to manually monitor their daily nutrition, moderate-to-vigorousphysical activity (MVPA), sleep and leisure-time screen time (LTST) throughout the intervention period, and tracking tools are available for all family members (parents, children, other family members). To encourage monitoring, small prizes (e.g., cookbooks, activitypromoting toys and games) are awarded at three points during the 16-session intervention period (e.g., on week 6 for tracking completed in weeks $1-5$, on week 11 for tracking completed in weeks $6-10$, and on week 16 for tracking completed in weeks $11-15)$. Families are eligible to receive prizes in each of the three time periods regardless of their consistency with monitoring in previous time frames. For both CBT and PEP, families strive to achieve the same lifestyle goals (please see Table 2), which are based on evidence-based recommendations [55-57].

Fundamental differences do exist between the CBT and PEP interventions. CBT is a theoretically-based therapy that focuses on the role that cognitive processes play in the maintenance of problem behaviours, mood states, and habits [58]. CBT also highlights the relationship between thoughts, feelings and actions, and utilizes techniques involving motivation, goal-setting, problem-solving, and knowledge/skill acquisition that can facilitate sustainable behaviour changes [59]. This intervention is designed to promote parental adoption of a more authoritative parenting style, which is exemplified by elements including rational decision-making, verbal give-and-take,

Table 2 Lifestyle goals for the CBT and PEP Versions of the PAC intervention

\begin{tabular}{|c|c|}
\hline \multirow[t]{3}{*}{ 1. Diet } & Daily vegetable and fruit intake: $\geq 5$ servings \\
\hline & $\begin{array}{l}\text { Daily grain product intake: } \geq 50 \% \text { servings } \\
\text { as whole grains }\end{array}$ \\
\hline & $\begin{array}{l}\text { Daily sugar-sweetened beverage intake: } \\
0 \text { servings }\end{array}$ \\
\hline \multirow[t]{2}{*}{ 2. Physical Activity } & Daily steps: $\geq 12,000$ (girls); $\geq 15,000$ (boys) \\
\hline & $\begin{array}{l}\text { Daily moderate-to-vigorous physical } \\
\text { activity: } \geq 90 \text { minutes }\end{array}$ \\
\hline 3. Sedentary Activity & Daily leisure time screen time: $\leq 90$ minutes \\
\hline
\end{tabular}

autonomous self-will, and disciplined conformity. CBT can improve parenting style and parent-child interactions [60], so group leaders work with parents who have more permissive (e.g., makes few demands) or authoritarian (e.g., restricts child autonomy) parenting approaches to help them to develop authoritative parenting skills. The skills learned in CBT help parents to identify and change the parenting mechanisms that maintain their children's current lifestyle habits; group leaders help parents to link knowledge, attitudes, thoughts, and feelings to behaviours and facilitate setting incremental goals that build on one another week-to-week in a manner that corresponds to parent motivation. CBT encourages consistent participation and collaboration between group leaders and participants; a Socratic questioning approach is also applied to help parents find their own answers to problems instead of having questions answered or problem-solved by group leaders [61]. To ensure the CBT-based version adhered to the main tenets of cognitive behavioural interventions, we consulted an international, three-member panel of clinical and research experts in CBT, obesity, and intervention development and evaluation. Their critical evaluation, feedback, and recommendations for revisions were incorporated into the curriculum.

In contrast, PEP is a knowledge-based intervention that is modeled after traditional nutrition and health education programs. Information regarding healthier parenting styles is provided in a didactic manner without directive leader-initiated goal-setting or problem-solving. In relation to CBT, PEP is a more passive intervention and there is limited focus on active skill building. The intervention is predicated on a more traditional approach that assumes behaviour change results from increased knowledge, although different activities are included for parents that encourage learning (individual activities, brain-storming, hands-on experiential learning) [62]. While group discussions and problem-solving are included within PEP, active integration of learned concepts in goal-setting and linking cognitions and behaviours to lifestyle changes are not integral. There is no active cognitive or behavioural skill building process embedded in the program. In relation to CBT, PEP requires less investment of energy and participation from parents, which many parents prefer. While PEP does not represent a true control group, its content and delivery are consistent with what many clinicians provide for weight management.

\section{Intervention fidelity}

One of the challenges in evaluating the effectiveness of lifestyle and behavioural interventions is optimizing the fidelity with which the interventions are delivered. In other words: During the trial, are the interventions 
delivered in the way in which they are intended? We are using multiple strategies to ensure standardization and consistency across parent/child cohorts as well as within and between intervention arms. Group leaders receive intervention delivery training through the use of standardized intervention manuals and weekly clinical meetings; following a manual and receiving reinforcement through team meetings ensures the interventions are delivered in a standard and consistent manner. Manualization of interventions is used extensively in health fields [63-66] and adds methodological rigor to our study design. Evaluation of delivery (adherence to intervention manuals) is achieved by session videotape. Three sessions within each of the CBT and PEP intervention arms are randomly chosen for videotaping and subsequently scored for adherence by two independent evaluators using a template created for the study that highlights study content and unique features of the interventions (See Table 3 for intervention adherence checklist). Inter- rater reliability is calculated using the Kappa statistic [67]. Issues with non-adherence to intervention integrity are addressed during weekly meetings.

\section{Outcome measures}

Child BMI z-score is the primary outcome for this study. Several investigations [68-72] have included BMI z-score as the primary outcome in pediatric weight management studies since it represents a clinically-meaningful indicator of weight status in childhood. Beneficial changes in this variable are linked to improvements in obesityrelated risk factors for chronic diseases including insulin resistance, dyslipidemia and high blood pressure [73,74]. The inclusion of this outcome is also informative when comparing effect sizes across studies.

Consistent with recommendations for evaluating the effects of pediatric obesity treatment [12,17], we are measuring a number of secondary physiological, behavioural, and psychosocial variables in families. Along with

Table 3 Intervention integrity checklist for the PAC intervention

\begin{tabular}{llc}
\hline Group Leader \#1: & Date (dd/mm/yyyy): \\
Group Leader \#2: & Rater: & Nes \\
\hline Content - Are the following content items addressed in the session? & No \\
\hline (Note: Details to be included by investigators; content items vary session-to-session) & Yes \\
\hline
\end{tabular}

Content - Did leaders follow the manual content throughout the session?

(Rater: Please read along in the manual during session to evaluate adherence to content).

Additional comments:

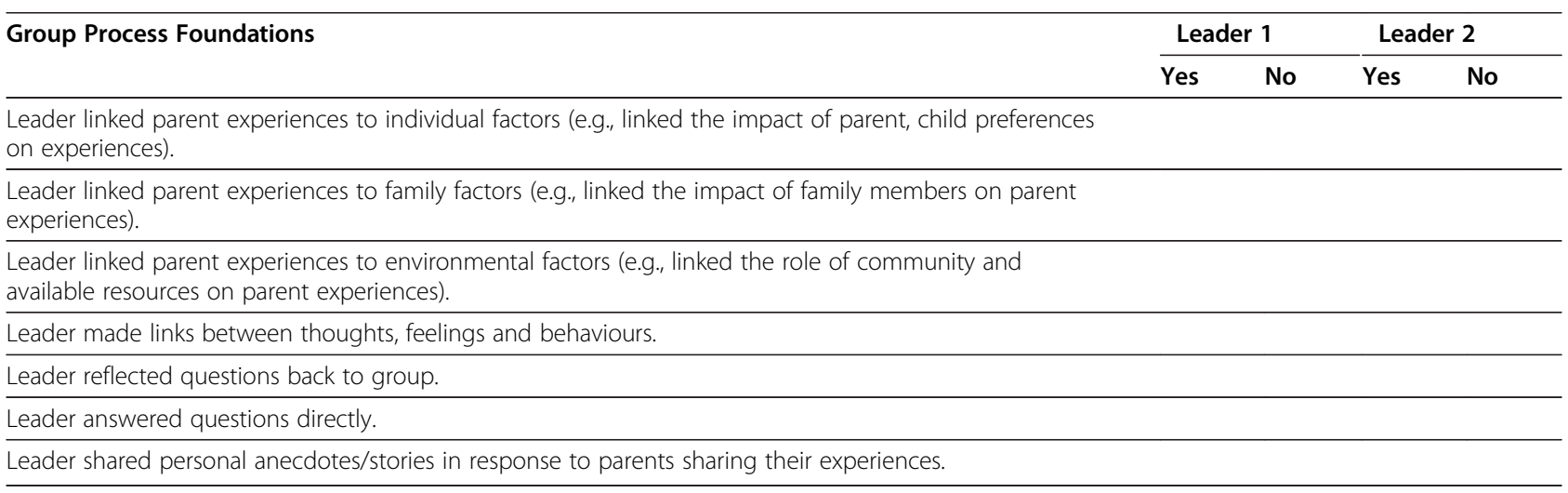


assessing nutrition and physical activity behaviours, anthropometry, and cardiometabolic risk factors, we are testing potential moderating (e.g., sex, age) and mediating (e.g., parents' lifestyle behaviors) variables to explore how different child and parent features interact with and respond to the different interventions and hypothesize how they contribute to changes in child health outcomes [75]. This is a valuable, but often overlooked process that provides a better understanding of the mechanisms of lifestyle change. This approach, in turn, allows our team to improve our interventions since we can distinguish between effective and ineffective intervention components [76].

\section{Physical exam, medical history, and demography}

Physical exams (for children) and a family medical history interview (for parents) are conducted by a pediatric endocrinologist at clinic intake. In addition, children's physical development are determined according to established guidelines [77,78]. Demographic data (e.g., date of birth, ethnicity, parents' education, household income) are also collected.

\section{Anthropometry}

Anthropometric measurements for children and parents are collected using a standardized protocol. Height is measured (without shoes) to the nearest $0.1 \mathrm{~cm}$ using a Seca 242 wall-mounted electronic stadiometer (Seca, Hamburg, Germany). Weight is assessed (wearing light clothing) to the nearest $0.1 \mathrm{~kg}$ using a Seca 644 medical scale. BMI is then calculated. For children, BMI data are entered into EpiInfo (Center of Disease Control and Prevention, Atlanta, GA) to determine sex- and age-specific BMI z-scores and percentiles. Waist circumference (WC) is measured at the top of the iliac crest using a spring-loaded Gulick anthropometric tape (FitSystems Inc., Calgary, $\mathrm{AB}$ ). WC data are acquired using the following protocol: Measurements are performed with the tape measure snugly positioned on, but not compressing, the skin; the spring is pulled until calibration tension is achieved on the tape. Clothing is positioned so the abdomen is exposed (bottom of shirt is positioned below the arms, which are crossed over the chest; pants/shorts are loosened and lowered slightly to reveal the hips). Recordings are taken at the end of a normal expiration and not during breath holding or abdominal muscle contractions. This procedure is repeated, and if the first and second values differ by more than $0.5 \mathrm{~cm}$, a third measurement is taken. Values are then averaged and recorded to the nearest $0.1 \mathrm{~cm}$.

\section{Dietary intake}

Dietary intake is recorded prospectively by children and parents over four consecutive days, and includes one weekend day. Once records are returned by families, a registered dietitian (RD) reviews all nutrition information with families to clarify items, validate portion sizes and name brands, and to ensure data completeness. Subsequently, these data are entered into the Food Processor Diet Analysis software program (ESHA Research, Salem, OR) to determine number of servings from Eating Well with Canada's Food Guide [55], total energy, macronutrient, and dietary fiber intakes.

\section{Physical activity and sedentary behaviours}

Children and parents measure prospectively their total physical activity using a pedometer (Yamax Digi-Walker SW-200) over a 7-day interval that overlaps with their dietary intake recording. Families receive training on proper pedometer positioning, data recording, and other physical activity monitoring details before the measurement interval starts. To ensure proper functioning, all pedometers are calibrated prior to use by way of a standardized step count test. Since pedometers do not capture information regarding physical activity intensity, children and parents complete simultaneously a 7-day physical activity record to document quality, quantity, and patterns of moderate-to-vigorous physical activity, leisure-time screen time (television, computer, video game, etc.), and sleep duration. Once records are returned, data are reviewed with families to ensure completeness and clarify durations and intensities of activities.

\section{Fasting blood sample}

A fasting blood sample $(\sim 3 \mathrm{ml})$ is retrieved from children to assess total cholesterol, HDL-cholesterol, LDLcholesterol, triglyceride, insulin, and glucose levels. Using insulin and glucose values, the homeostatic model of insulin resistance (HOMA-IR) is calculated [79]. Blood collections may occur at a number of different communitybased laboratories in the Edmonton-area; however, all analyses are completed centrally at the University of Alberta Hospital laboratory to ensure the same analytical procedures are used throughout the duration of this trial.

\section{Blood pressure}

With children in the seated position (and following a five minute rest), systolic and diastolic blood pressure (SBP and DBP, respectively) are measured oscillometrically with an appropriately-sized cuff on the right arm. SBP and DBP are measured three times with one minute intervals between each assessment. Representative values are based on the average of the three measures.

\section{Questionnaires}

Children complete the Piers-Harris Children's SelfConcept Scale (2 ${ }^{\text {nd }}$ edition) [80] to derive an assessment of their self-concept that focuses on the self-perceptions 
children have of themselves and their behaviors related to others, the Child Depression Inventory [81] to assess depressive symptomatology, and the Pediatric HealthRelated Quality of Life (PedsQL 4.0) to assess functioning related to physical, emotional, social and scholastic domains $[82,83]$. Parents complete the Parenting Stress Index, which assesses three subscales reflecting child and parent relationship characteristics and life stressors [84], the Child Behaviour Checklist [85], which probes child behavior and potential psychopathology, the Family Adaptability and Cohesion Evaluation Scales IV, which assesses family cohesion and flexibility dimensions, family communication and satisfaction [86], the Lifestyle Behaviors Checklist $[87,88]$ to survey common parental concerns regarding children's eating behaviors, physical activity, and other weight-related behaviors, and the parent proxy report of the PedsQL 4.0.

\section{Family enrolment, intervention dose, and attrition}

The study research coordinator record several studyspecific variables that will be used to populate the
CONSORT diagram (Figure 1). For instance, the total number of families recruited and enrolled in the study, parent attendance at each of the PAC sessions, and time of and reason for dropping out of the study are all documented.

\section{Sample size}

We are enrolling 90 families $(n=45$ families $\times 2$ PAC intervention arms) in this study. Based on our clinical experience, we anticipate a $33 \%$ level of attrition, which should yield post-intervention data on 60 families. With a total sample size of 60 families $(n=30$ per arm), we are able to detect a minimum difference of 0.5 in BMI $\mathrm{z}$-score change between the CBT and PEP intervention groups. To our knowledge, no experimental work has been done to define specific weight-related goals for pediatric obesity interventions. However, our 0.5 BMI $\mathrm{z}$-score difference is based on a review by Epstein and colleagues that suggested a reduction of this magnitude is clinically meaningful [89]. Sample size calculations were completed using PASS 2008 (www.ncss.com), and

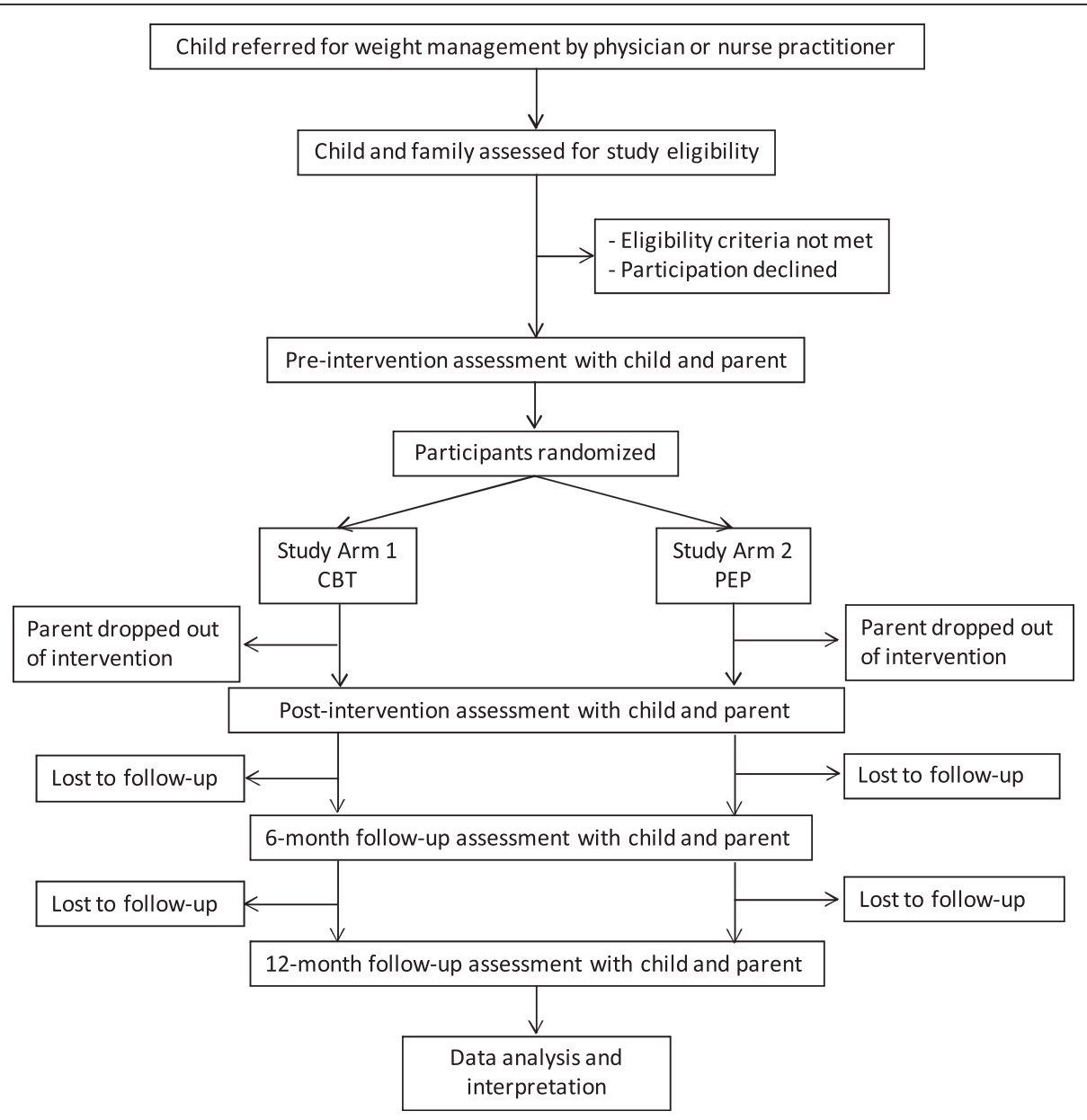

Figure 1 Participant flow diagram according to the CONSORT statement. 
assumed a standard deviation (SD) of 0.83 for each group, a one-sided significance level of 0.05 , and a desired power of $80 \%$. This SD was based on preliminary findings that included pre- and post-intervention BMI $\mathrm{z}$-score data [90]. Multiple linear regressions are able to detect an $\mathrm{R}^{2}$ value of $10 \%$ for the effect of intervention on percent change in BMI z-score at a 0.05 significance level with $80 \%$ power, assuming that the inclusion of five control variables explains $20 \%$ of the variability in change in BMI z-score.

\section{Randomization}

Parents are randomly assigned to either the CBT-based or PEP-based PAC intervention group following their completion of pre-intervention assessments, but before the initiation of the PAC sessions. Given that parents and their children are recruited and enrolled into the group-based interventions in several cohorts, we use a computer-generated, block randomization approach, which is completed by one of our research team members who has no direct contact with participants. Parents will be blinded to group assignment, and while they are aware that there are two groups of parents receiving the PAC intervention, they are unaware of the modality and methodological differences between CBT and PEP.

\section{Statistical analysis}

Data cleaning, analyses, figures, tables, and statistical sections for dissemination are conducted by a blinded biostatistician with the Biostatistics Consulting Group within the Women and Children's Health Research Institute (www.wchri.org) at the University of Alberta. Spotfire S + 8.2 (TIBCO Software Inc, 2010) and SAS 9.3 (SAS Institute Inc, 2010) will be used for analyses. Analyses are conducted both with PAC intervention completers only and with all participants (to evaluate effectiveness). Continuous variables are described by summaries (e.g., means, medians, ranges and SDs) and frequency distributions are determined for categorical variables. For the primary and secondary outcome variables, the percent change from pre- to post-intervention (as well as 6- and 12-months follow-up) for both groups is determined and summarized along with the 95\% confidence intervals (CIs) for mean percent change. Boxplots and histograms are used to display the percent change for these variables; bar charts are used for categorical variables. Our analyses are conducted separately for each mean percent change at each observation time (i.e., pre-intervention to post-intervention, pre-intervention to 6-month follow-up, and preintervention to 12-month follow-up). Statistical tests are set at conventional levels $(\mathrm{p}<0.05)$ and all analyses are intention-to-treat. Multiple imputation methods may be used in the event of missing data. To minimize the risk of bias, a research team member with no direct contact with enrolled families is leading the data analyses.

To compare interventions, one-sided independent samples Student's t-test assesses percent changes in BMI z-score (primary objective); if required, data transformations are used to ensure data normality. A similar process is used to determine intervention-mediated changes in other physiological, behavioural, and psychosocial outcomes (secondary objectives). In addition, the percentage of families with improved categorical outcomes (i.e., those who do/do not meet recommendations from Eating Healthy with Canada's Food Guide) is compared across interventions using a one-sided independent samples proportion tests. A multivariable linear regression model is developed for the primary outcome (percent change in BMI z-score) to determine the intervention group effect while controlling for potential confounders (i.e., cohort, percent attendance, household income). If any of the intervention groups include siblings, CIs are adjusted using variance inflation factors, and univariable or multivariable random intercept mixed effects models are used in lieu of Student's t-tests and multivariable linear regression, respectively. Analogous calculations are made to compare the percent change from pre-intervention to 12-month follow-up, although intervention attrition may reduce our power to detect a significant difference. Mixed effect models are developed to examine the effects of the interventions on primary and secondary outcomes over time. This approach allows all pre-intervention, post-intervention, and follow-up data to be included in our modeling. For all models, residual diagnostics are used to assess model assumptions and appropriate transformations and/or non-linear terms are included as necessary. Our reporting of study results is in accordance with the CONSORT statement [91].

\section{Discussion}

With overweight and obesity impacting the lives of at least two million boys and girls (and their families) in Canada [2,92], there is a clear need for effective interventions to promote successful pediatric weight management. This RCT builds on a solid evidence base of family-based interventions for managing pediatric obesity [89] as well as cognitive behavioral strategies to facilitate healthy changes in cognitions and lifestyle behaviors [59]. Contemporary research has demonstrated clearly that PAC interventions that are designed to manage pediatric health issues can lead to positive outcomes for both children and families [36-38], which includes a growing body of literature in the area of pediatric weight management [40-44]. This totality of evidence led us to hypothesize that children with obesity whose parents complete the CBT-based PAC intervention will achieve greater reductions in adiposity, improved lifestyle 
behaviours and psychosocial outcomes, and decreased cardiometabolic risk factors compared to children whose parents complete the PEP-based PAC intervention.

\section{Strengths and limitations}

The current study has a number of noteworthy strengths. First, we took a rigorous and systematic approach to the design of this RCT as well as the development and refinement our intervention materials for parents and group leaders. The manualized intervention materials for group leaders, external expert review of intervention materials, and plan to evaluate intervention fidelity enhance methodological rigour and provide confidence that the interventions are distinct from one another, which is needed to evaluate their differential effects. Second, if the CBT and/or PEP versions of the PAC intervention help parents to make positive changes, the manualization of intervention materials enables the dissemination and evaluation of PAC in other settings (i.e., primary care, public health). Existing partnerships between our team members and health services (e.g., Alberta Health Services; www.albertahealthservices.ca) and non-governmental (e.g., Canadian Obesity Network; www.obesitynetwork.ca) organizations should facilitate the dissemination and future delivery of the PAC intervention within the province of Alberta and across Canada. Third, because most of the boys and girls enrolled in this study are recruited from the PCWH, they are almost exclusively described as severely obese (BMI $\geq 99^{\text {th }}$ percentile or BMI $\geq 40 \mathrm{~kg} / \mathrm{m}^{2}$ ) [93]. Since much of the evidence in managing pediatric obesity includes less overweight and obese participants [89], the present RCT contributes important information regarding the impact of parent-based approaches for managing severe obesity in children. Finally, offering pediatric weight management interventions for parents exclusively represents an efficient model of care. Common sense dictates that the PAC interventions can be delivered using fewer resources (physical, human, financial) than interventions that include both parents and children. Since many pediatric weight management centers in Canada struggle to deliver health services with limited resources and infrastructure [14], interventions that are both efficient and effective are most desirable.

It is also important to acknowledge the potential limitations of this study. First, while we are implementing several retention strategies (e.g., regular telephone calls to confirm appointment and session attendance, modest incentives for families to complete outcome assessments at study time points), we know from our own clinical and research experience [48] and the published literature [94] that lack of engagement and attrition are common phenomena in pediatric weight management. These issues may have a negative impact on family recruitment and retainment within this RCT. To better understand and potentially address issues of engagement and attrition, we are currently completing an independent multicenter, qualitative study to interview 100 parents and 100 children and youth with obesity in order to understand parents' and children's decisions regarding engagement in and attrition from pediatric weight management centers [95]. These emerging data should help to inform decisions that should optimize recruitment and retention in the current study. Second, there is an increasing number and variety of services that relate to pediatric weight management (i.e., physical activity and exercise programs for families, community-based weight management programs, and outpatient nutrition) available to families in the Edmonton-area. Although this is advantageous from family and health services viewpoints, this reality decreases the number of local families who may be enrolled in our study. Third, our study is conducted in an outpatient clinic setting, so the health professionals performing many of the outcome assessments (e.g., anthropometry) know which families were randomized to the CBT and PEP intervention groups. Although they have no vested interest in the study as study co-investigators, this real-world environment introduces a potential source of bias (lack of assessor blinding; [52]) because all families receiving weight management care are regularly discussed during weekly case conference team meetings. Finally, to date, our discussions with families regarding a PAC approach for managing pediatric obesity have occasionally been met with resistance; since children present with the identified health concern, parents are sometimes taken by surprise with the primary role they are asked to play in the PAC intervention. Many parents embrace their leadership role in making and sustaining healthy changes within their families, although other parents will prefer that intervention efforts focus on children themselves or include both parents and children. As a consequence of these differing perspectives and intervention foci, some parents decline study participation.

The current study provides a unique opportunity by combining CBT and PAC within an intervention model to improve the health and well-being of children with obesity and their parents in a real-world, outpatient clinical setting. Findings from this research should contribute important insight into how health services can be provided effectively and efficiently to families in order to address pediatric obesity.

\section{Additional file}

Additional file 1: Appendix 1. Sample screenshot from the PAC Intervention Leader Manual, which includes the PowerPoint ${ }^{\circledR}$ slide presented to parents, bullet points for group leaders to emphasize/ paraphrase with parents, and references used to inform the development of the evidence-based curriculum. Appendix 2. Sample 
screenshot from the PAC Intervention Parent Manual, which includes the PowerPoint ${ }^{\circledR}$ slide presented to parents, space for parents to record the results of their goal-setting from the previous week, and probing questions to encourage parents to explore their thoughts, feelings and behaviours, and what (if anything) they would do differently next time.

\section{Competing interests}

In relation to the present research, all authors are in agreement that they have no financial or non-financial interests to declare.

\section{Authors' contributions}

GDCB conceived of the study (with ASN), co-authored a first draft of the manuscript (with KAA), and co-led the development of the PAC interventions (with RAK and ASN). KAA co-authored a first draft of the manuscript (with GDCB). RAK co-led the development of the PAC interventions (with GDCB and ASN) and assisted with study design as well as writing and editing the manuscript. RJR authored the sample size and statistical analysis sections of the manuscript and assisted with study design as well as writing and editing the manuscript. NLH assisted with study design as well as writing and editing the manuscript. JCS assisted with study design as well as writing and editing the manuscript. MMJ assisted with study design as well as writing and editing the manuscript. AMS assisted with study design as well as writing and editing the manuscript. ASN conceived of the study (with GDCB), co-led the development of the PAC interventions (with GDCB and RAK), and assisted with writing and editing the manuscript. All authors have read and approved the final manuscript.

\section{Acknowledgements}

The authors wish to acknowledge the contributions of the clinical and administrative team members who contributed to developing and refining the CBT- and PEP-based PAC interventions, including (in alphabetical order) Bobbi Barbarich, Amanda Beekman, Tesia Bennett, Laurie Gaboury, Dena Gushattey, Cheryl Krug, Erica Lauridsen, Kelly Mackenzie, Judy O'Leary, Rosann Skwarok, and Anna Stephenson. Funding for this research was provided by an Emerging Research Teams Grant from the Faculty of Medicine and Dentistry (University of Alberta) and Alberta Health Services. GDCB is supported by a Population Health Investigator Award from Alberta Innovates - Health Solutions (AlHS) and a New Investigator Award from the Canadian Institutes of Health Research (CIHR). RJR is supported by a Health Scholar Award from AlHS. ASN is supported by a New Investigator Award from the CIHR.

\section{Author details}

'8B, Pediatric Centre for Weight and Health, Edmonton General Continuing Care Centre, 11111 Jasper Ave, Edmonton, AB, CANADA T5KOL4. ${ }^{2} 8 B$, Pediatric Centre for Weight and Health, Edmonton General Continuing Care Centre, 11111 Jasper Ave, Edmonton, AB, CANADA T5KOL4. ${ }^{3}$ Community Programs East, Alberta Health Services, Northgate Health Centre, Edmonton, AB, CANADA. ${ }^{4}$ Edmonton Clinic Health Academy, Department of Pediatrics, University of Alberta, Rm 3-524, 1140587 Avenue, Edmonton, AB, CANADA T6G1C9. ${ }^{5}$ P3-20 S Van Vliet Centre, Faculty of Physical Education and Recreation, University of Alberta, Edmonton, AB, CANADA T6G2H9. ${ }^{6}$ W1-16 H Van Vliet Centre, Faculty of Physical Education and Recreation, University of Alberta, Edmonton, AB, CANADA T6G2H9. '8B, Pediatric Centre for Weight and Health, Edmonton General Continuing Care Centre, 11111 Jasper Ave, Edmonton, AB, CANADA T5KOL4. ${ }^{8} 406$ CSC Royal Alexandra Hospital, Edmonton, AB, CANADA T5H3V9. ${ }^{9} 3-526$ Edmonton Clinic Health Academy, Department of Pediatrics, University of Alberta, 1140587 Avenue, Edmonton, AB, CANADA T6G1C9.

Received: 3 July 2012 Accepted: 25 July 2012

Published: 6 August 2012

\section{References}

1. Wang Y, Lobstein T: Worldwide trends in childhood overweight and obesity. Int J Pediatr Obes 2006, 1:11-25.

2. Shields M: Overweight and obesity among children and youth. Health Rep 2006, 17:27-42.
3. Goran MI, Ball GD, Cruz ML: Obesity and risk of type 2 diabetes and cardiovascular disease in children and adolescents. J Clin Endocrinol Metab 2003, 88:1417-1427.

4. Dockray S, Susman EJ, Dorn LD: Depression, cortisol reactivity, and obesity in childhood and adolescence. J Adolesc Health 2009, 45:344-350.

5. Van Vlierberghe L, Braet C, Goossens L, Mels S: Psychiatric disorders and symptom severity in referred versus non-referred overweight children and adolescents. Eur Child Adolesc Psychiatry 2009, 18:164-173.

6. Wang F, Wild TC, Kipp W, Kuhle S, Veugelers PJ: The influence of childhood obesity on the development of self-esteem. Health Rep 2009, 20:21-27.

7. Vander Wal JS, Thelen MH: Eating and body image concerns among obese and average-weight children. Addict Behav 2000, 25:775-778.

8. Carr KA, Daniel TO, Lin H, Epstein LH: Reinforcement pathology and obesity. Curr Drug Abuse Rev 2011, 4:190-196.

9. Latner JD, Simmonds M, Rosewall JK, Stunkard AJ: Assessment of obesity stigmatization in children and adolescents: modernizing a standard measure. Obesity 2007, 15:3078-3085.

10. Puhl RM, Latner JD: Stigma, obesity, and the health of the nation's children. Psychol Bull 2007, 133:557-580.

11. Lau DC, Douketis JD, Morrison KM, Hramiak IM, Sharma AM, Ur E: Obesity Canada Clinical Practice Guidelines Expert Panel: 2006 Canadian clinical practice guidelines on the management and prevention of obesity in adults and children [summary]. CMAJ 2007, 176:S1-S13.

12. American Dietetic Association: Position of the American Dietetic Association: individual-, family-, school-, and community-based interventions for pediatric overweight. J Am Diet Assoc 2006, 106:925-945.

13. Institute of Nutrition, Metabolism and Diabetes, Canadian Institutes of Health Research: http://www.cihr-irsc.gc.ca/e/23293.html.

14. Ball GD, Ambler KA, Chanoine JP: Pediatric weight management programs in Canada: Where, what and how? Int J Pediatr Obes 2011, 6:e58-e61.

15. Ball GD, Willows ND: Definitions of pediatric obesity. CMAJ 2005, 172:309-310.

16. Faith MS, Van Horn L, Appel L, Burke LE, Carson JA, Franch HA, Jakicic JM, Kral TV, Odoms-Young A, Wansink B, Wylie-Rosett J: Evaluating parents and adult caregivers as "agents of change" for treating obese children: evidence for parent behavior change strategies and research gaps: a scientific statement from the American Heart Association. Circulation 2012, 125:1186-1207.

17. Spear BA, Barlow SE, Evvin C, Ludwig DS, Saelens BE, Schetzina KE, Taveras EM: Recommendations for treatment of child and adolescent overweight and obesity. Pediatrics 2007, 120:S254-S288.

18. Decaluwe V, Braet C, Moens E, Van Vlierberghe L: The association of parental characteristics and psychological problems in obese youngsters. Int J Obes 2006, 30:1766-1774.

19. Wrotniak BH, Epstein LH, Paluch RA, Roemmich JN: Parent weight change as a predictor of child weight change in family-based behavioral obesity treatment. Arch Pediatr Adolesc Med 2004, 158:342-347.

20. Heitzler CD, Martin SL, Duke J, Huhman M: Correlates of physical activity in a national sample of children aged 9-13 years. Prev Med 2006, 42:254-260

21. Zabinski MF, Daly T, Norman GJ, Rupp JW, Calfas KJ, Sallis JF, Patrick K. Psychosocial correlates of fruit, vegetable, and dietary fat intake among adolescent boys and girls. J Am Diet Assoc 2006, 106:814-821.

22. Francis $L A$, Birch $L L:$ Maternal influences on daughters' restrained eating behavior. Health Psychol 2005, 24:548-554.

23. Irwin JD, He M, Bouck LM, Tucker P, Pollett GL: Preschoolers' physical activity behaviours: parents' perspectives. Can J Public Health 2005, 96:299-303.

24. Spruijt-Metz D, Lindquist CH, Birch LL, Fisher JO, Goran Ml: Relation between mothers' child-feeding practices and children's adiposity. Am J Clin Nutr 2002, 75:581-586.

25. Baumrind D: Child care practices anteceding three patterns of preschool behavior. Genetic Psychol Monographs 1967, 75:43-88.

26. Holt NL, Moylan BA, Spence JC, Lenk JM, Sehn ZL, Ball GD: Treatment preferences of overweight youth and their parents in Western Canada. Qual Health Res 2008, 18:1206-1219.

27. Arredondo EM, Elder JP, Ayala GX, Campbell N, Baquero B, Duerksen S: Is parenting style related to children's healthy eating and physical activity in Latino families? Health Educ Res 2006, 21:862-871.

28. Stein Rl, Epstein LH, Raynor HA, Kilanowski CK, Paluch RA: The influence of parenting change on pediatric weight control. Obes Res 2005, 13:1749-1755. 
29. Wardle J, Sanderson S, Guthrie CA, Rapoport L, Plomin R: Parental feeding style and the inter-generational transmission of obesity risk. Obes Res 2002, 10:453-462.

30. Satter EM: Internal regulation and the evolution of normal growth as the basis for prevention of obesity in children. J Am Diet Assoc 1996, 96:860-864.

31. Koch FS, Sepa A, Ludvigsson J: Psychological stress and obesity. J Pediatr 2008, 153:839-844.

32. Epstein LH, Gordy CC, Raynor HA, Beddome M, Kilanowski CK, Paluch R: Increasing fruit and vegetable intake and decreasing fat and sugar intake in families at risk for childhood obesity. Obes Res 2001, 9:171-178.

33. Epstein LH, Myers MD, Raynor HA, Saelens BE: Treatment of pediatric obesity. Pediatrics 1998, 101:554-570.

34. Epstein LH, Valoski A, Wing RR, McCurley J: Ten-year follow-up of behavioral family-based treatment for obese children. JAMA 1990 264:2519-2523.

35. Epstein LH, Valoski A, Koeske R, Wing RR: Family-based behavioral weight control in obese young children. J Am Diet Assoc 1986, 86:481-484.

36. Grover M, Naumann U, Mohammad-Dar L, Glennon D, Ringwood S, Eisler I, Williams C, Treasure J, Schmidt U: A randomized controlled trial of an Internet-based cognitive-behavioural skills package for carers of people with anorexia nervosa. Psychol Med 2011, 20:1-11.

37. Schuster MA, Corona R, Elliott MN, Kanouse DE, Eastman KL, Zhou AJ, Klein DJ: Evaluation of Talking Parents, Healthy Teens, a new worksite based parenting programme to improve parent-adolescent communication about sexual health: randomised controlled trial. BMJ 2008, 337:a308.

38. Stewart-Brown S, Patterson J, Mockford C, Barlow J, Klimes I, Pyper C Impact of a general practice based group parenting programme: quantitative and qualitative results from a controlled trial at 12 months. Arch Dis Child 2004, 89:519-525

39. Golan M, Weizman A, Apter A, Fainaru M: Parents as the exclusive agents of change in the treatment of childhood obesity. Am J Clin Nutr 1998, 67:1130-1135

40. Golan M, Kaufman V, Shahar DR: Childhood obesity treatment: targeting parents exclusively v. parents and children. Brit J Nutr 2006, 95:1008-1015.

41. Boutelle KN, Cafri G, Crow SJ: Parent-only treatment for childhood obesity: a randomized controlled trial. Obesity 2011, 19:574-580.

42. Collins CE, Okely AD, Morgan PJ, Jones RA, Burrows TL, Cliff DP, Colyvas K, Warren JM, Steele JR, Baur LA: Parent diet modification, child activity, or both in obese children: an RCT. Pediatrics 2011, 127:619-627.

43. Magarey AM, Perry RA, Baur LA, Steinbeck KS, Sawyer M, Hills AP, Wilson G, Lee $A$, Daniels $L A$ : A parent-led family-focused treatment program for overweight children aged 5 to 9 years: the PEACH RCT. Pediatrics 2011, 127:214-222.

44. West F, Sanders MR, Cleghorn GJ, Davies PS: Randomised clinical trial of a family-based lifestyle intervention for childhood obesity involving parents as the exclusive agents of change. Behav Res Ther 2010, 48:1170-1179

45. Newton AS, Keaschuk RA, Ball GDC: Key ingredients for effective weight management: Integrating a family systems approach. In Focus on Family Relations in the $21^{\text {st }}$ Century. Edited by Yoon C.: Nova Science Publishers, Inc; 2007

46. Braet C, Tanghe A, Decaluwe V, Moens E, Rosseel Y: Inpatient treatment for children with obesity: weight loss, psychological well-being, and eating behavior. J Pediatr Psychol 2004, 29:519-529.

47. Braet C, Tanghe A, Bode PD, Franckx H, Winckel MV: Inpatient treatment of obese children: a multicomponent programme without stringent calorie restriction. Eur J Pediatr 2003, 162:391-396.

48. Ball GDC, Mackenzie KA, Newton MS, Alloway CA, Slack JM, Plotnikoff RC, Goran Ml: One-on-one lifestyle coaching for managing adolescent obesity: Experience from a real-world, clinical setting. Paediatr Child Health 2011, 16:346-355.

49. Sox HC, Goodman SN: The methods of comparative effectiveness research. Annu Rev Public Health 2012, 33:425-445.

50. Centers for Disease Control and Prevention: CDC Growth Charts. Department of Health and Human Services. Atlanta: CDC: National Center for Health Statistics; 2000.

51. Methodology Committee of the Patient-Centered Outcomes Research Institute (PCORI): Methodological standards and patient-centeredness in comparative effectiveness research: the PCORI perspective. JAMA 2012, 307:1636-1640.
52. Pildal J, Chan AW, Hróbjartsson A, Forfang E, Altman DG, Gøtzsche PC: Comparison of descriptions of allocation concealment in trial protocols and the published reports: cohort study. BMJ 2005, 330:1049.

53. Bartholomew LK, Parcel GS, Kok G, Gottlieb NH: Intervention mapping: Designing theory- and evidence-based health promotion programs. Mountain View, CA: Mayfield; 2001.

54. Ball GDC, Keaschuk RA, Newton AS: Using intervention mapping to develop the Parents as Agents of Change pediatric weight management intervention. BMC Health Serv Res, In Review.

55. Health Canada: Eating Well with Canada's Food Guide. Ottawa: Health Canada; 2007

56. Tudor-Locke C, Pangrazi RP, Corbin CB, Rutherford WJ, Vincent SD, Raustorp A, Tomson LM, Cuddihy TF: BMI-referenced standards for recommended pedometer-determined steps/day in children. Prev Med 2004, 38:857-864.

57. Health Canada: Canada's Physical Activity Guide for Youth. Ottawa: Health Canada; 2002.

58. Cooper Z, Fairburn CG: Cognitive-behavioral treatment of obesity. In Handbook of obesity treatment. Edited by Wadden TA, Stunkard AJ. New York, NY: Guilford Press; 2002.

59. Beck JS: Cognitive therapy: Basics and beyond. New York, NY: Guilford Press; 1995.

60. Mendlowitz SL, Manassis K, Bradley S, Scapillato D, Miezitis S, Shaw BF: Cognitive-behavioral group treatments in childhood anxiety disorders: the role of parental involvement. J Am Acad Child Adolesc Psychiatr 1999, 38:1223-1229.

61. Miller JR, Rollnick S: Motivational interviewing: Preparing people for change. 2nd edition. New York, NY: Guilford; 2002.

62. Glanz K, Rimer BK, Lewis FM: Health behavior and health education: Theory, research, and practice. 3rd edition. San Francisco, CA: Jossey-Bass; 2002.

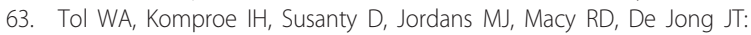
School-based mental health intervention for children affected by political violence in Indonesia: a cluster randomized trial. JAMA 2008, 300:655-662.

64. Allen LA, Woolfolk RL, Escobar Jl, Gara MA, Hamer RM: Cognitive-behavioral therapy for somatization disorder: a randomized controlled trial. Arch Intern Med 2006, 166:1512-1518.

65. Asarnow JR, Jaycox LH, Duan N, LaBorde AP, Rea MM, Murray P, Anderson M, Landon C, Tang L, Wells KB: Effectiveness of a quality improvement intervention for adolescent depression in primary care clinics: a randomized controlled trial. JAMA 2005, 293:311-319.

66. Anonymous: The Diabetes Prevention Program. Design and methods for a clinical trial in the prevention of type 2 diabetes. Diabetes Care 1999, 22:623-634.

67. Fleiss JL: Statistical methods for rates and proportions. 2nd edition. New York, NY: John Wiley and Sons; 1981.

68. Edwards C, Nicholls D, Croker H, Van Zyl S, Viner R, Wardle J: Family-based behavioural treatment of obesity: acceptability and effectiveness in the UK. Eur J Clin Nutr 2006, 60:587-592.

69. Reinehr T, de Sousa G, Toschke AM, Andler W: Long-term follow-up of cardiovascular disease risk factors in children after an obesity intervention. Am J Clin Nutr 2006, 84:490-496.

70. Rudolf M, Christie D, McElhone S, Sahota P, Dixey R, Walker J, Wellings C: WATCH IT: a community based programme for obese children and adolescents. Arch Dis Chil. 2006, 91:736-739.

71. Temple JL, Wrotniak BH, Paluch RA, Roemmich JN, Epstein LH: Relationship between sex of parent and child on weight loss and maintenance in a family-based obesity treatment program. Int J Obes 2006, 30:1260-1264.

72. Stewart L, Houghton J, Hughes AR, Pearson D, Reilly JJ: Dietetic management of pediatric overweight: development and description of a practical and evidence-based behavioral approach. J Am Diet Assoc 2005, 105:1810-1815.

73. Ford AL, Hunt LP, Cooper A, Shield JP: What reduction in BMI SDS is required in obese adolescents to improve body composition and cardiometabolic health? Arch Dis Child 2010, 95:256-261.

74. Reinehr $\mathrm{T}$, Kleber M, Toschke AM: Lifestyle intervention in obese children is associated with a decrease of the metabolic syndrome prevalence. Atherosclerosis 2009, 207:174-180.

75. Baranowski T, Lin LS, Wetter DW, Resnicow K, Hearn MD: Theory as mediating variables: why aren't community interventions working as desired? Ann Epidemiol 1997, 7:S89-S95. 
76. Dunn AL, Resnicow K, Klesges LM: Improving measurement methods for behavior change interventions: opportunities for innovation. Health Educ Res 2006, 21:i121-i124.

77. Marshall WA, Tanner JM: Variations in the pattern of pubertal changes in boys. Arch Dis Child 1970, 45:13-23.

78. Marshall WA, Tanner JM: Variations in pattern of pubertal changes in girls. Arch Dis Child 1969, 44:291-303.

79. Matthews DR, Hosker JP, Rudenski AS, Naylor BA, Treacher DF, Turner RC Homeostasis model assessment: insulin resistance and beta-cell function from fasting plasma glucose and insulin concentrations in man. Diabetologia 1985, 28:412-419.

80. Piers-Harris Children's Self-Concept Scale, $2^{\text {nd }}$ edition (Piers-Harris 2). http://portal. wpspublish.com/portal/page?_pageid=53,112628\&_dad=portal\&_schema=PORTAL.

81. Children's Depression Inventory, $2^{\text {nd }}$ edition (CDI 2). http://www.mhs.com/ product.aspx?gr=edu\&prod=cdi2\&id=overview.

82. Varni JW, Seid M, Kurtin PS: PedsQL 4.0: reliability and validity of the Pediatric Quality of Life Inventory version 4.0 generic core scales in healthy and patient populations. Medical Care 2001, 39:800-812.

83. Varni JW, Seid M, Rode CA: The PedsQL: measurement model for the pediatric quality of life inventory. Medical Care 1999, 37:126-139.

84. Abidin RR: Parenting Stress Index. 3rd edition. Lutz, FL: Psychological Assessment Resources; 1995

85. Achenbach TM, Rescorla LA: Manual for the ASEBA School-Age Forms \& Profiles. Burlington, VT: University of Vermont, Research Center for Children, Youth, \& Families; 2001

86. Olson DH, Gorall DM, Tiesel JW: Family Adaptability and Cohesion Evaluation Scales (IV). 2004. http://www.friendsnrc.org/download/outcomeresources/ toolkit/annot/face.pdf.

87. West F, Morawska A, Joughin K: The Lifestyle Behaviour Checklist: Evaluation of the factor structure. Child Care Health Dev 2010, 36:508-515.

88. West F, Sanders MR: The Lifestyle Behaviour Checklist: A measure of weight-related problem behaviour in obese children. Int J Pediatr Obes 2009, 4:266-273.

89. Epstein LH, Paluch RA, Roemmich JN, Beecher MD: Family-based obesity treatment, then and now: twenty-five years of pediatric obesity treatment. Health Psychol 2007, 26:381-391.

90. Keaschuk RA, Newton MS, Ball GDC: Parental stress and childhood obesity. Childhood and Adolescent Obesity 2008 - How we live, how we learn and how we work: Implications for the prevention and treatment of childhood obesity. Vancouver, BC: Abstract presented at the academic conference; 2008.

91. Moher D, Schulz KF, Altman DG: The CONSORT statement: revised recommendations for improving the quality of reports of parallel-group randomized trials. Lancet 2001, 357:1191-1194.

92. Annual Demographic Statistics, 2005. ON: Ottawa; 2006.

93. Skelton JA, Cook SR, Auinger P, Klein JD, Barlow SE: Prevalence and trends of severe obesity among US children and adolescents. Acad Pediatr 2009, 9:322-329.

94. Skelton JA, Beech BM: Attrition in paediatric weight management: a review of the literature and new directions. Obes Rev 2011, 12:e273-e281.

95. Ball GDC, Chanoine JC, Morrison K, Legault L, Holt NL, Gokiert R, Sharma AM: Should I stay or should I go? Understanding overweight children and their families referred for and discontinuing weight management care. Ottawa, ON: Operating Grant, Canadian Institutes of Health Research; 2010-2013:222098.

\section{Submit your next manuscript to BioMed Central and take full advantage of:}

- Convenient online submission

- Thorough peer review

- No space constraints or color figure charges

- Immediate publication on acceptance

- Inclusion in PubMed, CAS, Scopus and Google Scholar

- Research which is freely available for redistribution

Submit your manuscript at www.biomedcentral.com/submit
C Biomed Central 